\title{
COMUNICAÇÃO
}

\section{POSSÍVEIS INTERVENÇÕES DO PSICÓLOGO EDUCACIONAL: O GRUPO COMO ESPAÇO DE MUDANÇAS EDUCATIVAS*}

\author{
POSSIBLE INTERVENTIONS OF THE \\ EDUCATIONAL PSYCHOLOGIST: THE GROUP \\ AS A PLACE OF EDUCATIONAL CHANGES
}

Edla Grisard Caldeira de ANDRADA ${ }^{1}$

\begin{abstract}
RESUMO
O trabalho foi uma intervenção em Psicologia Educacional junto a uma professora e 21 crianças em uma instituição de Educação Infantil. 0 grupo investigado não era considerado como pertencente à instituição e a professora não sabia o que fazer com ele. Partindo do pressuposto da psicologia histórico-cultural, o objetivo era modificar a compreensão da professora em relação ao seu papel de mediadora, para que pudesse dar novos significados às relações ali entabuladas, visando à aprendizagem e ao desenvolvimento. A intervenção foi feita na sala com as crianças e a professora, durante 12 encontros elaborados em cooperação com a professora, objetivando a criação de Zonas de Desenvolvimento Proximal como procedimento da intervenção. Ao final dos encontros, foi possível perceber modificações nas interações professora-crianças, pois passaram a ocupar diferentes lugares na sala, atuavam em diferentes papéis e, portanto foram estabelecidos, novos significados para as interações.
\end{abstract}

Palavras-chave: psicologia histórico-cultural; zona de desenvolvimento proximal; interação professora-crianças.

\footnotetext{
(*) Trabalho apresentado no I Seminário Internacional de Educação, Em Cianorte, Paraná, 2001.

(1) Universidade Federal de Santa Catarina Endereço: Largo Benjamin Constant, 691 apto 403 Centro - Florianópolis - CEP 88015-390 - E-mail: edla@floripa.com.br - Fone: (48) 224-5202
} 


\begin{abstract}
This work was an intervention in Educational Psychology with a teacher and 21 children in a Child Care Institution. The group investigated was not considered as part of the institution and the teacher did not know what to do with the children. Based on the presupposition of the historicalcultural psychology, the objective of this work was to change the teacher's comprehension of concept of mediation, as well as to give new meanings to the relations in the classroom, focusing the processes of learning and development. The intervention was done in the classroom with the teacher and the children, during 12 encounters elaborated in cooperation with the teacher, having the objective of creating Zones of Proximal Processes as a procedure of intervention. In the end of the encounters it was possible to perceive changes in the interactions between teacher and children, they occupied different places in the classroom, played different roles and so new meanings to the interactions were given.
\end{abstract}

Keywords: historical-cultural psychology; zone of proximal processes; teacher-children interactions.

\section{INTRODUÇÃO}

O processo de constituição do sujeito vem sendo investigado por pesquisadores de diferentes orientações teórico-metodológicas em Psicologia, dentre as quais destaca-se aqui a Psicologia histórico-cultural (Pino, 1993 e 1995; Góes, 1993; Góes, Smolka e Pino, 1998; Zanella, 2000). Nesta perspectiva, considera-se que o sujeito se constitui nas relações com outros, via atividade humana, sendo esta necessariamente mediada por ferramentas técnicas ou semióticas (Pino, 1995).

Na literatura histórico-cultural o "outro" é tido como essencial no processo de constituição do sujeito e, segundo Góes (1993), a ação do "outro" é conhecida como uma ação partilhada que ajuda no estabelecimento de pontes, num processo denominado bridging $\mathrm{e}$ na criação de uma estrutura andaime, ou scaffolding, que dá suporte ao sujeito da relação.

Nessa perspectiva, a dimensão histórica e social aponta para a necessidade de a investigação acerca dos processos de constituição do sujeito focar contextos sociais específicos, ou seja, estudar as interações com outros sujeitos nos contextos nos quais ocorre a mediação e nos quais se criam estruturas de suporte e pontes.

Vislumbrando essa reflexão, a idéia desse trabalho surgiu a partir de uma experiência de dois anos, então como estagiária de psicologia em um Centro de Educação Infantil (CEI) municipal, parte integrante de um centro comunitário de um bairro periférico em Florianópolis. O trabalho foi desenvolvido com o grupo das crianças mais velhas no $\mathrm{CEI}$, entre 6 e 8 anos, que iam para a escola num período do dia e, no outro, lá permaneciam. A pergunta que me serviu de base para o trabalho foi a seguinte: "como é significado pela professora o papel de mediadora na prática pedagógica?".

Tendo observado o grupo em interação, este trabalho objetivou modificar a compreensão da professora em relação ao seu papel de mediadora, para que pudesse resignificar as interações com e entre as crianças, visando à aprendizagem e ao desenvolvimento. Os objetivos específicos foram: descrever como a professora significa seu próprio trabalho, levantar aspectos acerca da instituição e das interações que constituem o seu dia-a-dia e 
possibilitar a reflexão por parte da professora, sobre o seu papel no grupo.

Assim, algumas perguntas fizeram-se necessárias: o que é "mediação" para a professora? Como se dá a mediação na sua prática pedagógica? Como a professora pode criar zonas de desenvolvimento proximal com seus alunos?

A princípio, a professora parecia não entender o significado de mediadora, uma vez que desenvolvia um trabalho que desconstrói e desconsidera o sujeito ativo e participante, dando lugar, por exemplo, a um sujeito-aluno passivo, que recebe ordens e que não faz escolhas (Andrada, 2001).

Assim, supondo o trabalho com a instituição como um todo, o trabalho visou, como afirma Marlene Guirado, resgatar o caráter de:

"conhecimento de relação (e não do indivíduo)", como forma de intervenção psicológica (...) não mais a relação bipessoal cliente-terapeuta, mas o conjunto das relações de uma instituição concreta, com objeto e objetivos próprios, com características particulares (como por exemplo, o atendimento à população em abandono e carência, o atendimento à saúde ou à educação da população), com uma determinada distribuição de tempo, espaço e relação de poder, que existem independentemente da ação do psicólogo" (Guirado, 1987, p.66).

\section{BREVES CONSIDERAÇÕES TEÓRICAS}

Os estudos acerca dos processos de ensino e aprendizagem, que seguem a perspectiva histórico-cultural, salientam a importância da atividade mediada, que promove a apropriação dos signos e dos instrumentos e o surgimento dos processos psíquicos superiores (vide Oliveira, 2000; Andrada, 2001; Zanella e Andrada, 2001).
Um fato importante a ser considerado é que, para Vygotsky, a interação social e os processos psicológicos dependem das formas de mediação, definindo desenvolvimento em termos de surgimento e transformação das diversas formas de mediação utilizadas pelo sujeito nas interações que estabelece com o mundo físico e social. Desenvolvimento e aprendizagem estão, portanto, completamente ligados, segundo Zanella:

"para especificar melhor a inter-relação aprendizagem/desenvolvimento e a importância das conquistas ontogenéticas para a constituição do homem, Vygotsky concebeu o desenvolvimento humano como compreendendo dois níveis: o primeiro éo que compreende o conjunto de atividades que a criança consegue resolver sozinha. Este nível é indicativo de ciclos de desenvolvimento já completos, isto é, refere-se às funções psicológicas que a criança já construiu até determinado momento. O segundo nível de desenvolvimento compreende o conjunto de atividades que a criança não consegue realizar sozinha, mas que, com a ajuda de alguém que Ihe dê algumas orientações adequadas (um adulto ou outra criança mais experiente), ela consegue resolver (...) o segundo nível de desenvolvimento indica o desenvolvimento prospectiva-mente e refere-se ao futuro da criança" (Zanella, 2001, p.97).

Constatando esses dois níveis de desenvolvimento, Vygotsky estabeleceu o conceito de Zona de Desenvolvimento Proximal, apontando para o fato de que "(...) tanto o adulto quanto o parceiro mais experiente exercem importante papel no desenvolvimento da criança, pois auxiliam na resolução de problemas que a criança não consegue, de forma autônoma, resolver" (Zanella, 2001, p.107).

Portanto, torna-se imprescindível entender tanto o conceito de mediação como o de instrumentos mediadores da atividade humana. 
De acordo com Wertsch (1988, p.33), em 1933 Vygotsky "chegou a dizer que o tema central da psicologia é o tema da mediação".

Ao formular a regra geral do desenvolvimento cultural, Vygotsky afirma que uma função psíquica sempre aparece duas vezes: uma vez entre as pessoas, no social, e outra para o próprio sujeito, como relatam Smolka, Góes e Pino (1998):

"Em suas formulações sobre a gênese social e a natureza do desenvolvimento, Vygotsky fala das relações mútuas como o contexto da formação do indivíduo. $O$ papel da mediação social no desenvolvimento configura-se em termos fortes: o caminho do objeto para a criança e da criança para o objeto passa por outra pessoa" (p.155).

Dessa forma, o adulto, consciente de seu papel de mediador, precisa reconhecer a zona de desenvolvimento real das crianças e criar com elas zonas de desenvolvimento proximal que permitam saltos qualitativos em seu desenvolvimento. $\mathrm{O}$ adulto precisa estar ciente do papel fundamental que exerce no desenvolvimento das crianças, ou seja, precisa reconhecer que sua ajuda, suas perguntas, sua participação junto às crianças na execução de tarefas é o suporte necessário para que, num segundo momento, a criança execute a mesma tarefa com autonomia.

Partindo do princípio de que a criança, desde seu nascimento, se apropria de conhecimentos via interações sociais, é preciso salientar a responsabilidade das instituições de Educação Infantil em colocar à disposição das crianças informações necessárias ao seu pleno desenvolvimento. $O$ ingresso de uma criança numa instituição de caráter educativo trará para ela novas experiências e interações distintas das que está acostumada a vivenciar com os adultos responsáveis. Novas e diferentes experiências, por sua vez, vão gerar novos significados para os sujeitos numa relação em que, interagindo com tais significados, os transformam e se transformam.

\section{MÉTODO}

Caracterizando o grupo como o espaço em que "a criança desabrocha sua natureza, é também em grupo que podemos ter espaço de trasnformá-la" (Gayotto, 1992, p.39), assim como transformar as relações ali entabuladas, visando à aprendizagem e ao desenvolvimento do grupo como um todo. Desta forma, ainda segundo Gayotto, o processo educativo deve explorar a rotina, em grupo, da seguinte maneira:

"incentivando a convivência recíproca entre as crianças; favorecendo o desempenho de papéis ativos das crianças; permitindo a iniciativa pessoal e grupal; criando condições para que os mais velhos convivam com os mais novos, através de brincadeiras e de cuidados com os menores; deixando as crianças explorarem e descobrirem o espaço da creche com limites, ocupados, e acompanhados pelos adultos, para que elas se descubram livres, mas não abandonadas" (idem, p.40).

Partindo das propostas acima descritas, o processo de intervenção visou usar a interação como instrumento de trabalho, uma vez que "os participantes, ao compartilharem o processo de construção de uma unidade de trabalho comum, trazem para o campo grupal diferentes experiências de vida, distintos conhecimentos da realidade (...)" (idem, p.49).

Interação é, portanto, comunicação, troca de idéias e de emoções, requer considerar o outro, perceber-se mutuamente. Desta forma, o mediador que está atento a esse processo cria situações em que cada criança pode desempenhar um papel ativo no grupo, tomar iniciativa, ser reconhecida como sujeito de importância para o grupo. 
O primeiro contato com o CEI deu-se em uma reunião pedagógica e teve como objetivo escutar as demandas do grupo de professoras. A proposta inicial de intervenção, elaborada a partir dos relatos das professoras nessa reunião, era identificar entre cinco a sete crianças com dificuldades de interação, que apresentavam condutas-problema (a violência era uma das maiores queixas das professoras), e trabalhar com o grupo dos "escolhidos" fora do contexto da sala. Entretanto, estabelecer antes da experiência critérios de escolhas dos sujeitos implicava fortalecer os critérios de exclusão das crianças, que para as professoras eram "crianças problema". Durante as observações, verificou-se que tal proposta era pouco significativa, pois as relações que precisavam ser resignificadas eram justamente aquelas que aconteciam na sala.

Foi necessário estar na sala, inserir-se em seu complexo de interações e procurar diferenciá-las e estudá-las como parte de um movimento historicamente construído. Foi preciso contextualizar a instituição e perceber as relações que esta estabelece com a comunidade em que está inserida, que nela vive e interioriza valores e conteúdos que influenciarão na formação das crianças.

Assim, foram feitas 10 observações da turma, de duas horas de duração, em momentos diferentes: na sala de aula, na hora do almoço e no parque, na entrada e na saída, observando o grupo todo. Durante esse período acompanhou-se o grupo em todas as suas atividades e foi anotada, em diário de campo, a história do grupo através das manifestações de discurso, gestos, tom de voz, posturas corporais, enfim, tudo o que pudesse decifrar o processo interacional.

Após as observações, elaborou-se com a professora outra proposta de intervenção, caracterizando assim, desde o primeiro momento, a criação de zonas de desenvolvimento proximal com a profissional. Tal proposta deveria incluir o grupo todo e a própria professora, criando pontes entre esta e a psicóloga, criando estruturas de suporte para que a professora pudesse, ao longo do ano, junto com as crianças, dar novos significados às interações neste grupo e deste grupo com a creche.

Surgiram então algumas questões que nortearam a proposta de intervenção elaborada em conjunto: 1) qual o papel deste GT na formação dessas crianças? 2) como as pessoas deste grupo (professora e crianças) se reconhecem como individualidade inserida num grupo (reconhecimento do "eu" e do "outro")? 3) quais as atribuições que a instituição dispensa a este grupo?

Esta reflexão redirecionou a intervenção no sentido de, definitivamente, abandonar a idéia inicial - de retirar crianças-problema e trabalhar com elas fora da sala - e desenvolver grupos operativos com todas as crianças e a professora, de duas horas por semana, proporcionando atividades que contribuíssem para a formação de uma nova identidade grupal (reconhecimento do "eu" e do "outro") dentro da sala, do grupo na creche e da creche na comunidade.

Como um dos procedimentos era o de criar zonas de desenvolvimento proximal com a professora, cada encontro seguinte era elaborado em conversa com ela, mediante as observações do encontro anterior, assim como mediante as anotações de ambas as profissionais, feitas durante e após as atividades e que revelavam as expectativas das crianças, seus relatos e suas vontades. Tal conversa tinha como objetivo possibilitar o exercício de reflexão sobre o papel de mediadora, criando um "campo interpsicológico onde significações são socialmente produzidas e paulatinamente apropriadas (...) numa confrontação ativa e cooperativa de compreensões variadas a respeito de dada situação" (Zanella, 2001, p.113). Os encontros eram geralmente feitos fora da sala, permitindo que as crianças e a professora pudessem explorar o ambiente do CEI. 


\section{O GRUPO}

Eram 21 crianças, entre 6 e 8 anos de idade, que já freqüentavam a escola em um período. Todas moravam nos morros nos arredores do CEI, um bairro periférico, de classe pobre. Seus pais e mães trabalhavam como faxineiros, empregadas ou porteiros, em sua maioria. A professora, 35 anos, tendo feito apenas o magistério, mas com mais de 15 anos de experiência na área, tinha uma condição econômica mais favorável do que as crianças; eu, a mediadora, estagiária de Psicologia Educacional da Universidade Federal de Santa Catarina, 27 anos, classe média.

O grupo era "estranho" a todo o CEI, visto pelas professoras como um "quebra-galhos" para os pais que não tinham onde deixar as crianças no período em que elas estavam fora da escola. Além disso, a professora não sabia muito bem o que fazer com as crianças e estas tinham apenas a noção que ali deveriam permanecer até que seus responsáveis viessem pegá-las.

Talvez esse grupo tenha adquirido tal característica por ter sido formado sem planejamento e participação efetiva dos profissionais, uma vez que surgiu por determinação da gerência do CEI, que alegou estar atendendo a um pedido dos pais. A falta de sentimento de pertença (Sarmento e Pinto, 1997) desse grupo na creche como um todo revelava-se inclusive no espaço físico: uma sala no andar inferior da creche, portanto, isolada de todas as outras salas, impedindo a interação desse grupo com as outras crianças. A sala era pequena, com 4 mesas, sendo 4 ou 5 crianças por mesa. Possuía pouca ventilação e iluminação; quadro negro grande, armário para o material, escrivaninha da professora, cabides para pendurar pastas e toalhas.

As crianças no GT11 eram dispostas por idade e série escolar, divididas segundo seu nível escolar nos momentos de "atividade pedagógica", entendida como atividades limitadas ao lápis e papel (Gayotto, 1992). A disposição das crianças em pequenos grupos teoricamente facilitaria a interação entre elas crianças; porém, a professora não permitia que essa interação ocorresse. Ela as proibia de conversarem, pedia silêncio, dizia que não podiam dividir a revista com o colega, etc. Apesar de sentarem juntas, não havia trabalho em grupo organizado, somente tentativas por parte das crianças, que buscavam em alguns momentos ajudar o colega, ou demonstravam curiosidade acerca do trabalho do outro. A interação entre as crianças ocorria mais na hora do parque, sem nenhuma monitoração por parte da professora, que se limitava a olhar de longe.

Quanto aos padrões de comunicação, nesse grupo ocorria o seguinte: as crianças, ao se encontrarem com a professora após o almoço, comentavam muito sobre o que havia se passado até então, fazendo queixas em relação aos colegas e à auxiliar. Por parte da professora, havia um padrão de respostas vazias do tipo "tá, já sei...", sem preocupação em entender o que realmente estava acontecendo com as crianças e o que desejavam comunicar através de seus comportamentos.

A professora mostrava-se incapaz de fazer uma leitura do grupo à procura de sinais que favoreciam a aprendizagem, o desenvolvimento, o interesse, a motivação e a integração das crianças. Além disso, ela falava sempre de pé, atrás da mesa e custava muito a atender ao chamado da criança; às vezes, nem atendia, fazendo com que a criança desistisse. A auxiliar, por sua vez, mantinha contato com as crianças somente através de gritos e pedidos de silêncio. Não conversava, nem se interessava pelas reais necessidades das crianças; enfim, não participava do mundo infantil e de suas brincadeiras.

Em relação aos "métodos de ensino", termo utilizado pela professora, observou-se que, para executar a tarefa, a professora primeiramente separava as crianças por série, 
agrupando-as conforme o nível de "capacidade", ao mesmo tempo que separava "os que incomodam muito". Antes da explicação, a professora exigia silêncio, pois "não se pode pensar e falar ao mesmo tempo". Era extremamente metódica ao explicar a tarefa, exigindo que as crianças mantivessem uma ordem exata na seqüência da atividade: "primeiro buscar o material, depois esperar pelos outros, depois abrir o material, etc". Durante a execução da tarefa, as crianças não tinham qualquer acompanhamento ou orientação. Ainda assim, demonstravam interesse pela atividade, envolvendo-se na tarefa, apesar de muitas vezes apresentarem dificuldades para concluí-la.

O assunto trabalhado era descontextualizado, sem ligação com as situações vividas pelas crianças em sua realidade social. Aparentemente não havia planejamento nem das atividades nem do tempo dispensado para a realização das mesmas. Outras atividades da creche, como tomar café ou a limpeza da sala, tinham prioridade sobre os "trabalhos pedagógicos" perpetuando, dessa forma, o histórico caráter assistencialista das creches públicas.

\section{O PROCESSO DE INTERVENÇÃO}

Tornou-se importante repensar o espaço da sala e o tempo que o grupo permanecia junto, visualizando o cotidiano do mesmo. 0 procedimento visava instrumentalizar a professora, orientando-a na leitura do grupo a partir da realidade observada, resgatando também o seu papel enquanto mediadora da educação e do cuidado. Era preciso incluir essa professora no grupo, fazendo com que ela e a auxiliar interagissem com as crianças sem a preocupação excessiva com o controle ou com a execução de tarefas, permitindo-se simplesmente estar com o grupo e brincar com as crianças.

Partindo do pressuposto e que na ação e interação "os sujeitos adquirem consciência de si como pessoas e como grupos" (Gayotto, 1992, p.70), as primeiras atividades objetivaram ampliar a consciência de si, uma "condição necessária para que surja a consciência de grupo" (idem, p.70). Num segundo momento, quando crianças e professora já se percebiam como sujeitos na ação do grupo, as atividades visavam à compreensão do "significado da participação em grupo com objetivos comuns, objetivos ligados aos interesses comuns dos participantes, tendo em vista a condição social do grupo na sociedade" (idem, p.71).

Assim, iniciou-se no dia 19/04 com a apresentação de todo o grupo a partir da confecção de crachás. Era uma tarefa individual, porém o espaço da sala foi modificado de forma que todos pudessem se ver na execução da tarefa e pudessem compartilhar os mesmos lápis, canetas, idéias, imagens, etc. Aqui, a mediadora intervinha no sentido de ampliar o vocabulário das crianças, partindo do que elas já conheciam sobre o significado de um crachá, para que serve, se elas já viram, onde e quem usava, para dar sentido ao uso de crachá na sala, como instrumento que identifica o "eu". Também era preciso ajudá-las a negociar o material, mostrando a importância de aguardar a vez, trocar canetas, etc. A professora, como em todas as atividades, era convidada a sentar com o grupo e também executar a tarefa, mostrando-se como mais uma pessoa no grupo e ao mesmo tempo, interagindo como mediadora junto às crianças.

Após a confecção, todos mostravam seus crachás e diziam ao grupo o que tinham feito. A mediação deu-se no sentido de oferecer novos signos e seus significados a partir das falas das crianças, trabalhando junto com o grupo o sentido que cada uma inferia da palavra usada por quem apresentava seu desenho. Foi possível observar que, quando uma criança tida como "calada" era convidada a falar, esta se sentia temida, sem graça, e isso foi a indicação de que o próximo encontro deveria ainda trabalhar com a consciência de si e identificação do eu no grupo, tarefa que a 
professora também executaria durante a semana até o próximo encontro.

No dia 29/04 cada criança desenhou em envelopes brancos a "sua cara", sendo que os envelopes serviriam para cada criança guardar suas produções ao longo do semestre. O material continuou a ser coletivo, porém as crianças foram divididas em pequenos grupos. Desta vez, a mediadora quase não interveio nas negociações das crianças, porém nas apresentações dos envelopes foi dada ênfase ao significado compartilhado e imprimido aos envelopes e ao sentido particular que cada criança deu à sua criação. Como todos queriam falar ao mesmo tempo, sugerindo que precisavam de mais espaço para se expressar, o encontro seguinte objetivou possibilitar a cada um no grupo um momento de fala, de exposição.

A atividade elaborada para o dia 05/05 permitiu a cada criança, em um palco imaginário, apresentar-se como se fosse um personagem infantil de que gostasse muito (dos quadrinhos, dos livros de contos de fada, etc). Tal tarefa foi surpreendente tanto para a mediadora como para a professora, pois os personagens apresentados pelas crianças eram todos televisivos, artistas famosos como "Latino", "Carla Perez" e "Sheila do Tchan"; o cantor "Daniel"; "Bochecha"; "Silvester Stalone", etc. Isso indica que a significação de infância nesse grupo passa pela sensualidade, pela agressividade, pela fama, aparência física, enfim, um significado construído pela televisão e por elas apropriado.

Diante disso, a hipótese de trabalho para o próximo encontro foi de possibilitar uma reflexão acerca das escolhas feitas pelas crianças, ou seja, fazer com que elas olhassem para o personagem escolhido e percebessem características que Ihes eram próprias, construindo individualmente uma noção do "eu". A partir do individual de cada criança, estabeleceu-se um perfil mais geral do grupo, permitindo que as crianças se reconhecessem dentro do grupo ao qual pertenciam.
No dia 12/05 cada criança escreveu em um pedaço de papel as características dos personagens escolhidos. Esbarrou-se na dificuldade de escrever da maioria das crianças, porém, como mediadora, e contando com a professora também nesse papel, as crianças foram ajudadas particularmente, tendo modelos de como escrever, imitando inicialmente os adultos e depois fazendo por si próprias. Algumas com menos dificuldades foram colocadas junto aos mais experientes, criando entre eles próprios zonas de desenvolvimento proximal. Depois, em conjunto, escreveramse as características do grupo todo, evitando repetições, em uma folha de papel pardo colada na parede e demos o título de "Nosso grupo tem...". Nesse momento, a mediadora fez um movimento no sentido de dar novos significados às características individuais para o cartaz do grupo, transformando, junto com as crianças, expressões como "sou forte" em "coragem" ou "força" e discutindo o que elas entendem por tais expressões.

As palavras que surgiram no cartaz intitulado "Nosso Grupo tem" foram as seguintes: inteligência, beleza, coragem, força jovem, briga, bagunça, cuidado, estudo. Tal cartaz ficou na parede da sala e a professora usou as palavras em outras atividades durante a semana. Uma observação interessante sobre o movimento do grupo surgiu no momento em que as crianças levaram o cartaz para a sala, pois mostraram cuidado e interesse em ajudar. Isso suscitou, em termos de análise, a compreensão de que as crianças, uma vez estimuladas a produzir e vendo o resultado, podem trabalhar em grupo e cooperar umas com as outras em harmonia.

$\mathrm{Na}$ atividade passada ficou faltando conhecer o sentido privado que as crianças dão às palavras escolhidas. Dessa forma, no dia 19/05 as crianças foram divididas em três grupos sendo que cada grupo deveria procurar fotos em revistas que representassem os adjetivos por elas escolhidos no encontro anterior. Cada um dos três grupos ficou com 
um conjunto de palavras afins: amor/felicidade/ cuidado; inteligência/gente estudiosa; beleza/ força jovem/amizade. As crianças participaram ativamente dentro de cada subgrupo, contribuindo através de trocas de figuras para a confecção dos cartazes dos outros subgrupos. A mediação acontecia nos subgrupos, quando a mediadora questionava junto às crianças sobre quais figuras significavam as palavras do grupo.

A apresentação das figuras foi muito interessante, as crianças estavam juntas, muito à vontade para mostrar seus trabalhos, para apresentá-los, ou para falar o que quisessem sobre a atividade. Uma das crianças, que geralmente gritava para ser escutada, no momento em que lhe foi dada a chance de falar, disse "não, hoje eu não quero falar nada". Outra criança comentou que os cartazes ficaram parecidos pois "nós tudo é um grupo!"; sua voz saiu tão forte que até ele se surpreendeu. Nesta atividade elas se sentiram reconhecidas perante o grupo, puderam falar de si, pois sua fala tinha sentido, e puderam escutar o outro, por que também o outro tinha algo significativo para compartilhar. A partir dessa abertura, o trabalho seguiu no sentido de proporcionar uma atividade em que as crianças pudessem expressar-se de maneiras variadas, através de dramatização de histórias infantis.

No dia 26/05 três histórias foram dramatizadas: Tuca, o tucano ecologista; Louro, o papagaio dançarino; e Sr. Urso: o formigueiro. (Coleção Animaizinhos, Bolsa Nacional do Livro, 1998). As crianças escolheram os personagens da história de forma tranqüila, através de negociação de papéis e da percepção de que para montar uma peça, cada um deveria fazer uma parte. Os personagens eram construídos a partir dos significados que o grupo lhes imprimia.

Ao dramatizarem, as crianças estavam entusiasmadas e atentas tanto aos papéis que representaram como às peças que assistiram, enquanto espectadores. Após as apresentações, elas falaram dos seus sentimentos em relação à atividade: "fiquei emocionado, quase chorei!"; "foi muito legal"; "eu fiquei com vergonha, mas gostei"; "achei lindo". A partir dessas falas, conversamos sobre seus sentimentos, suas habilidades já conquistadas (ler, montar uma peça, dramatizar, mostrar-se para os outros, etc.) e de como elas podem ser sujeitos ativos perante o real. Com esta atividade, um ciclo do trabalho foi finalizado, que corresponde à análise e significação de cada criança dentro do grupo, da sua individualidade, do seu "eu" que junto com os "outros", compõe o grupo. A partir de então, as hipóteses de trabalho partiram do reconhecimento desse grupo dentro do CEI, tendo como ponto de partida uma reunião de pais que logo aconteceria.

No dia 02/06, ao confeccionarem os convites para a reunião de pais, as crianças mostraram-se ansiosas ao saber que seus pais iriam receber e capricharam nos desenhos, escreveram coisas que representam o "grupo de psicologia" para eles, tais como: "é muito amoroso", "é legal". No momento em que estavam preparando seus convites, surgiram algumas queixas tipo "ele está copiando meu desenho", queixas estas trabalhadas na própria mesa onde estavam as crianças. A mediadora fez com que as crianças olhassem para os desenhos e observassem que, apesar de terem a mesma idéia, eram extremamente diferentes. Assim, chegaram à conclusão de que "cada um é cada um, mesmo que o desenho seja parecido".

Dia 09/06 foi a preparação de uma outra sala para a reunião com os pais, que aconteceu nesse mesmo dia. As crianças foram divididas em três grupos e distribuímos o material para que produzissem um recado aos pais ou responsáveis. Elas estavam motivadas pela idéia de que seus pais receberiam um desenho seu, desejando boas-vindas, com a sala toda preparada por eles. Suas mensagens continham frases como "que bom que você veio", ou "boa reunião". Conversamos sobre o significado de uma reunião de pais, o que elas achavam que iria ser conversado, etc. 
Quem terminava o recado ajudava na arrumação da sala e na colagem dos cartazes e confecção do varal com os crachás. Todos estavam envolvidos e muito prestativos. A troca de ambiente facilitou o trabalho com as crianças, especialmente porque a sala delas é extremamente pequena para o número de crianças. Os pais responderam os recados com desenhos e dizeres, e a professora surpreendeu as crianças no dia seguinte com um mural de recados dos pais. A partir desse momento, a hipótese de trabalho foi de construir com as crianças um perfil da creche, verificando como a criança se vê dentro da creche, que valor tem esse momento da vida para ela.

Iniciamos o dia 10/06 resgatando a idéia do crachá, que serviu como um demonstrativo da identificação de cada um, "o retrato de cada um". Conversou-se então sobre a identificação da creche e o lugar que ela ocupa na vida das crianças, relembrando o que a creche possui, quais os espaços que elas gostam, quais os espaços que elas não gostam. Foi pedido que montassem um desses lugares com a argila, porém, elas não queriam se ater ao tema proposto. Isto sinalizou um possível desinteresse da criança pela creche, demonstrando que ela realmente percebia a creche como um lugar em que ficava apenas para que os pais pudessem trabalhar, não como um espaço para se desenvolver, brincar, crescer e aprender.

A partir disso, elaborou-se uma atividade para que as crianças escolhessem suas brincadeiras favoritas e desenvolvessem as regras das brincadeiras em pequenos grupos (dia 30/06). Mediamos o significado das regras na creche, como são construídas e por que existem. Finalizamos o grupo com as brincadeiras que ele mesmo escolheu e construiu as regras (dia 07/07). No dia 14/07 foi feita uma festinha com balões, bolo, refrigerante, etc. O término desse grupo foi celebrado numa roda onde cada um disse o que gostou ou o que não gostou durante o "grupo da psicologia", e o significado sobre o que era esse grupo foi colocado em pauta.

\section{CONCLUINDO}

Pode-se inferir que as instituições de Educação Infantil hoje reproduzem a herança da era moderna que com maestria promoveu a cisão entre o trabalho e lazer, pensamento e emoção, ciência e arte, saber e fazer. O papel de mediador do professor é engolido pela programação burocrática e repetitiva de uma prática assistencialista, que visa suprir apenas as necessidades de alimentação e higiene das crianças, ou de uma prática escolarizada que visa reproduzir na Educação Infantil a disciplinarização das escolas de ensino fundamental (Oliveira, 1995; Cerisara, 1999, Andrara, 2001).

Surge um paradoxo: com a excessiva programação do cotidiano da instituição, operase a desapropriação do sujeito. Porém, é neste mesmo espaço que podemos descobrir que a instituição escolar não é somente continuidade e homogeneidade, mas que é também espaço de ruptura. É neste espaço que;

"as atividades heterogêneas que caracterizam o cotidiano escolar são empreendidas e articuladas por sujeitos individuais (professores, alunos, diretores, etc.) que levam para a escola práticas e saberes que provêm de outros âmbitos pertencentes à sua história de vida. (...) cada escola, então, é construída diariamente pela integração de seus agentes (...) Estes sujeitos se apropriam de formas diferentes das coisas, dos conhecimentos, das regras institucionais. Enquanto alguns se apropriam das normas (...) obedecendo à rigidez dos espaços e tempos reservados a atividades pré-determinadas, outros conseguem abrir espaço para expressão individual e se apropriam 
das regras do jogo que forem necessárias à sua sobrevivência na escola, sem que isso impeça seu trabalho criativo. Podem até burlar aquelas rotinas e normas vigentes em que não acreditam, criando uma forma própria de atuar, estabelecendo, em seu próximo círculo de relações e influências, uma prática alternativa. É a situação, por exemplo, de um professor que, ao fechar a porta de sua sala de aula, cria rotinas próprias que mais se aproximem de suas crenças e das necessidades de seus alunos" (Warschauer, 1993, p.30).

Dessa forma, fechando a porta da sala e criando junto com a professora uma rotina a partir do conhecimento das crianças e das suas necessidades, à medida que os encontros aconteciam, as crianças passaram a tomar mais a sua voz, podendo "ser mais indivíduos" dentro do grupo. A professora, por sua vez, também passou a interagir de maneira nova, primeiramente imitando a mediadora, possibilitando negociação entre as crianças, ouvindo seus desejos, construindo com elas zonas de desenvolvimento proximal e, conseqüentemente, ampliando seus conhecimentos e seu repertório.

Assim, ela pôde perceber, por exemplo, que os rotulados como "burros" eram na verdade muito inteligentes e tinham "sacadas incríveis", como ela mesma assinalou. A aprendizagem teve lugar nessa sala e, com ela, o desenvolvimento. Relembrando Vygotsky, "a consciência resulta da apropriação das significações produzidas em contextos interpsicológicos, a partir da atividade instrumental dos sujeitos em interação"(Zanella, 2001, p.82).

No final do trabalho a professora escreveu o seguinte:

"O GT11 é uma turma de alunos que freqüentam as primeiras e segundas séries do colégio Getúlio Vargas. Como ficam um período em sala de aula com atividades pedagógicas no colégio, chegam na creche agitados, demonstrando desinteresse por qualquer atividade proposta. Como professora procurei propor atividades pedagógicas (reforço escolar), e também trazer para o grupo novas alternativas de trabalho (teatro, coral, etc.). Procurei criar um "espaço prazeroso", onde os alunos quisessem ficar, já que os pais procuravam um lugar para ter onde deixar seus filhos (ficar, por ficar). O grupo de psicologia trouxe para o GT11 atividades em que jogos, teatro, desenhos eram constantes, mas vinham sempre acompanhados de um trabalho em que o respeito pelo outro, o saber esperar, o dividir estavam também presentes. Com essas atividades o grupo começou a se ver como um grupo que trabalha junto, onde tem um pouco de cada um para que a coisa dê certo. Nas diferentes atividades observei: que novos grupos iam surgindo (reparar no outro, sair do "grupinho" de sempre); que os pais estavam tomando conhecimento dos encontros; que os mais "parados" estavam ocupando seu lugar no grupo e se queixavam quando contrariados; que o dia do encontro era aguardado com ansiedade; que o GT11 agora é um grupo que reivindicará "outras coisas". Passei a ver o GT11 como um grupo que está mais calmo, que sabe o que quer e o que não quer. Pude vero quanto alguns alunos "cresceram", suas idéias, suas falas me chamam a atenção. "Nós" estamos crescendo um pouco mais a cada dia, enquanto indivíduos e como grupo de trabalho".

Evidenciou-se, portanto, a necessidade de estabelecer com a professora zonas de desenvolvimento proximais que possibilitem a formação de novas maneiras de lidar com a construção de conhecimento. Para Moll (1996) "o papel do adulto é o de através da fala exploratória ou outras mediações sociais (...) assistir às crianças no sentido de que estas 
assumam o controle sobre a própria aprendizagem" (apud Zanella, 2001, p.110).

Dessa forma, através da mediação do adulto a criança deve ter a possibilidade de se conscientizar de suas habilidades e conhecimentos já construídos até o momento; além disso, o adulto deve criar situações em que essa criança se constitua enquanto um sujeito ativo e interativo (idem, p.110). É bom lembrar, conforme Zanella aponta, que Vygotsky não especificou que modalidades de auxílio os professores devem fornecer, embora mencione colaboração e orientação na introdução de elementos iniciais da solução da tarefa. Para ele,

"O central (...) parece ser as possibilidades intelectuais construídas e diretamente relacionadas a como as crianças interagem com outras em determinados contextos de solução dos problemas. Destaca ainda que as crianças internalizam e transforma com a ajuda que recebem podendo, eventualmente, usa-las como guia para direcionar a solução subseqüente de outros problemas" (idem, p.112).

Finalmente, faz-se necessário ressaltar que um trabalho deste porte não deseja firmar a idéia de que cada professor precise ser 'monitorado' por outro profissional para resignificar sua relação com seu grupo, mas deseja afirmar que uma formação continuada pode acontecer mediante o estabelecimento de zonas de desenvolvimento com grupos de professores, fazendo com que sintam, na prática, o que significa ser mediador.

Ficou evidente que o profissional da psicologia escolar tem fundamental importância no trabalho junto ao professor, não mais numa relação bipessoal com as crianças-problema, mas especialmente no sentido de resignificar as relações da sala, permitindo ao professor ver o grupo como o espaço das mudanças educativas, possibilitando novas trocas e trocas mais saudáveis.

\section{REFERÊNCIAS BIBLIOGRÁFICAS}

ANDRADA, E.G.C. Entre o dever-fazer e o viver da criança: a significação das regras nas interações bebês-professora-bebês. UFSC, 2001. Dissertação de Mestrado, Programa de pós-graduação em Psicologia.

CERISARA, A.M. Educar e cuidar, por onde anda a educação infantil? In: Perspectiva: Florianópolis, v.17, Especial, p.1-38,1999.

GAYOTTO, M.L.C. (Org.) Creches: desafios e contradições da criação coletiva da criança pequena, SP: Ícone, 1992.

GÓES, M.C.R. Os modos de participação do outro nos processos de significação do sujeito. In: Temas em Psicologia, Sociedade Brasileira de Psicologia, 1, p.1-15, 1993.

GÓES, M.C.; SMOLKA, A.L.; PINO, A. A constituição do Sujeito: uma questão recorrente? In: WERTSCH, P. DELRIO, e ALVAREZ. Estudos Socioculturais da Mente, POA: Artes Médicas, p.143-158, 1998.

GUIRADO, Marlene. Psicologia Institucional. SP: EPU, 1987.

OLIVEIRA, Z.M.R. (Org.) Educação Infantil: muitos olhares, SP: Cortez, 1995.

OLIVEIRA, Z.M.R. (Org.) A criança e seu desenvolvimento: perspectivas para se discutir a educação infantil. SP: Cortez, 2000.

PINO, A. Processos de Significação e Constituição do Sujeito, In: Temas em Psicologia, $n^{\circ} 1$, p.17-23, 1993.

PINO, A. Semiótica e Cognição na Perspectiva Histórico Cultural. In: Temas em Psicologia, n², p. 31-39, 1995.

SARMENTO, M. e PINTO, M. As crianças, contextos e identidades. Coleção Infans, Centro de Estudos da Criança, Universidade do Minho, 1997. 
VYGOTSKY, L.S. The genesis of higher mental function. In: WERTSCH, J. The concept of activity in Soviet psychology. New York: Sharpe, 1981.

WARSCHAUER, Cecília. A Roda e o Registro: uma parceria entre o professor, alunos e conhecimento. RJ: Paz e Terra, 1993.

WERTSCH, J. Vygotsky y la formacción de la mente. Barcelo: paidos, 1988.

ZANELLA, A.V. Aproximaciones a la Temática de la Constitución del Sujeto en Vygotsky y E. Morin. In: Psykhe, v.9, n², p.75-81, 2000.

ZANELLA, A.V. Vygotsky: contribuições à Psicologia e o conceito de Zona de Desenvolvimento Proximal. Itajaí: Univali, 2001.

ZANELLA, A.V.; ANDRADA, E.G.C. Processos de significação, brincadeira e relações professora-bebês: problematizando a questão da constituição do sujeito, 2001. (artigo encaminhado para publicação). 
